\section{Um estudo epidemiológico da efetividade de um programa educativo para o controle da esquistossomose em Minas Gerais}

Maria Fernanda Lima-Costa

Laboratório de Epidemiologia e Antropologia Médica

Centro de Pesquisas René Rachou

Fundação Oswaldo Cruz

30190-002, Belo Horizonte, MG, Brasil

Departamento de Medicina Preventiva e Social

Faculdade de Medicina

Universidade Federal de Minas Gerais, Belo Horizonte, MG

\section{Henrique L Guerra}

Laboratório de Epidemiologia e Antropologia Médica

Centro de Pesquisas René Rachou

Fundação Oswaldo Cruz, Belo Horizonte, MG

Josélia O. A. Firmo

Laboratório de Epidemiologia e Antropologia Médica

Centro de Pesquisas René Rachou

Fundação Oswaldo Cruz, Belo Horizonte, MG

Fabiano Pimenta Jr.

Centro Nacional de Epidemiologia

Fundação Nacional de Saúde

\section{Elizabeth Uchoa}

Laboratório de Epidemiologia e Antropologia Médica

Centro de Pesquisas René Rachou

Fundação Oswaldo Cruz, Belo Horizonte, MG

Departamento de Psiquiatria e Neurologia

Faculdade de Medicina

Universidade Federal de Minas Gerais, Belo Horizonte, MG

\section{Auxílio financeiro}

Ministério da Saúde/Fundação Nacional de Saúde/Banco Mundial e Conselho Nacional de Desenvolvimento Científico e Tecnológico, através de bolsas de produtividade em pesquisa (Processos № 301056/94-3 e 520337/96-4)

\section{Resumo}

O objetivo deste estudo foi determinar o impacto de um programa de mobilização comunitária (atividades educativas) na primeira comunidade em Minas Gerais (Patis) na qual esta atividade foi desenvolvida, como parte do programa nacional de controle da esquistossomose (PCE/PCDEN). A prevalência da infecção nesta localidade (área estudada), entre 1984 e 1994, foi comparada àquela observada em Muquem (área controle). Um estudo seccional foi realizado para determinar as características demográficas (idade, sexo, tempo de residência), características dos domicílios (fonte de água, destino de dejetos, presença de chuveiro e distância aos córregos), padrões de contatos com águas e conhecimentos sobre prevenção/transmissão da esquistossomose nas duas comunidades. Em Patis foram também examinados os fatores associados aos contatos com águas nos últimos 12 meses. Embora a prevalência inicial e final da infecção tenha diferido em Patis (43,2 e 17,2\%, respectivamente) e na área controle $(38,2$ e $33,7 \%)$, verificou-se que esta diferença não podia ser atribuída à mobilização comunitária, uma vez que a queda na prevalência da infecção já havia ocorrido antes do início destas atividades. Os conhecimentos sobre a transmissão e prevenção da esquistossomose foram altos em ambas as comunidades, mas esses conhecimentos não estiveram associados aos padrões de contatos com águas. Somente a faixa etária de 10 19 (OR= 4,0; IC 95\%: 2,1-7,4) e $\geq 20$ anos (OR=1,9; IC 95\%: 1,1-3,2) e sexo masculino $(\mathrm{OR}=2,1$; IC 95\%: 1,4-3,5) apresentaram associações independentes com contatos com águas. Concluiu-se que o programa de mobilização comunitária não foi efetivo: (a) para transmitir conhecimentos sobre a transmissão e prevenção da esquistossomose, (b) para transformar esses conhecimentos em mudanças de comportamento e/ou (c) para reduzir a prevalência da infeção pelo $S$. mansoni.

Palavras-chave: Avaliação de programas de saúde. Impacto. Efetividade. Esquistossomose. Schistosoma mansoni. Epidemiologia. Educação para a saúde. Mobilização comunitária. 


\section{Abstract}

The objective of the present study was to determine the impact of a community mobilization program (educational activities) in the first community of Minas Gerais (Patis) where this activity was developed, as part of the national schistosomiasis control program (PCE/PCDEN). The prevalence of the infection in Patis (study area) between 1984 and 1994 was compared with that of Muquem (control area). A cross sectional study was carried out to determine demographic characteristics (age, gender and time of residence in the area), household features (water supply, disposal system, presence of shower and distance from streams), water contact patterns and knowledge on prevention/transmission of schistosomiasis in the two communities. In Patis we also examined the factors associated with water contact in the previous 12 months. The prevalence of the infection in the two periods differed for the two communities compared (43.2 and $17.2 \%$ in Patis, and 38.2 and $33.7 \%$ in Muquem, respectively). However, the reduction in the prevalence of the infection in the study area could not be attributed to community mobilization because it had already occurred before the beginning of these activities. Knowledge on prevention and transmission of the infection was high, but this knowledge was not associated with the water contact pattern. Only the $10-19$ years $(\mathrm{OR}=4.0$; IC 95\%: 2.1-7.4) and $\geq 20$ years (OR=1.9; IC 95\%: 1.1-3.2) age groups, and the male gender (OR=2.1; IC 95\%: 1.4-3.5) were independently associated with water contact. We concluded that the community mobilization program was ineffective: (a) to deliver information on prevention and transmission of schistosomiasis, (b) to transform this knowledge on behavioral changes, and/or (c) to reduce the prevalence of Schistosoma mansoni infection.

Keywords: Evaluation of health programs. Impact. Effectiveness. Schistosomiasis. Schistosoma mansoni. Epidemiology. Health Education. Community mobilization.

\section{Introdução}

Entre 1984 e 1994 diversas atividades foram realizadas no Estado de Minas Gerais como parte do programa nacional de controle da esquistossomose (PCE/PCDEN). Este programa foi desenvolvido pela Fundação Nacional de Saúde (FNS), com financiamento do Banco Mundial. Os recursos anuais para o mesmo foram estimados em cerca de dois milhões de dólares americanos, tendo sido cerca de $5 \%$ deste valor destinado a atividades de educação para a saúde a partir de $1988^{1}$

O programa nacional de controle da esquistossomose é baseado fundamentalmente no tratamento de indivíduos infectados (ou também de não infectados, dependendo das características da área endêmica). As atividades de controle em Minas Gerais concentraram-se inicialmente em seis municípios situados na Bacia do Rio São Francisco, totalizando 131.000 habitantes, distribuídos em 916 localidades. Nesta região, foram realizados 487.000 exames de fezes, 178.000 tratamentos com oxamniquine, 226.000 capturas de caramujos e consumidos $222 \mathrm{~kg}$ de moluscicidas nos dez anos iniciais do PCE/PCDEN ${ }^{2}$.

No final dos anos 80, o Ministério da Saúde determinou que atividades educativas, através de programas de mobilização comunitária (atividades de Informação, Educação e Comunicação), fossem incorporadas ao PCE/PCDEN, como um dos componentes do mesmo ${ }^{1}$. O primeiro programa de mobilização comunitária no Estado de Minas Gerais foi desenvolvido no ano de 1989, em uma pequena localidade denominada Patis, situada na Bacia do Rio São Francisco. A partir de então, essas atividades foram disseminadas para outras áreas endêmicas neste estado, sem que nenhuma avaliação fosse feita da experiência anterior ${ }^{3}$.

A efetividade de programas educativos para o controle da esquistossomose é pouco conhecida $^{4-7}$. As principais razões para que os esforços de avaliação tenham falhado já foram discutidas em trabalho anterior ${ }^{6}$ e são semelhantes no Brasil e em outros pa- 
íses em desenvolvimento. Quais sejam: 1) avaliação baseada nas atividades realizadas, em lugar da avaliação do impacto e mudanças na comunidade; 2) demonstração insuficiente de que as mudanças foram resultado do programa educativo e não devidas a outros fatores; e 3) descrição insuficiente dos programas educativos.

Neste trabalho é apresentado um modelo simples de avaliação do impacto de um programa de mobilização comunitária para o controle da esquistossomose em uma situação comum na maioria dos países em desenvolvimento, em que os investigadores não têm controle sobre a intervenção realizada e possuem recursos financeiros limitados para a sua avaliação. Este trabalho é parte da avaliação das atividades educativas do PCE/PCDEN solicitada pelo Ministério da Saúde em 1995 à comunidade acadêmica, com apoio do Banco Mundial. O objetivo do presente trabalho é determinar a efetividade do programa de mobilização comunitária desenvolvido pelo Ministério da Saúde, como parte do PCE/PCDEN em Minas Gerais, no que se refere a: 1) redução da prevalência da infecção pelo Schistosoma mansoni; 2) transmissão de conhecimentos sobre a transmissão e prevenção da esquistossomose e 3) mudanças de padrões de contatos com águas potencialmente infectadas. Um objetivo adicional do estudo é determinar se conhecimentos sobre a transmissão e prevenção da infecção influenciam os contatos com coleções hídricas.

\section{Metodologia}

\section{Localidades estudadas}

Este trabalho foi desenvolvido em duas localidades (Patis e Muquem) situadas no Município de Mirabela, no norte do Estado de Minas Gerais. A localidade de Patis foi escolhida por ter sido a primeira neste Estado a ter um programa de mobilização comunitária desenvolvido dentro das atividades do PCE/PCDEN ${ }^{3}$. A comunidade de Muquem foi escolhida como área controle pelas seguintes razões: 1) o programa de mobilização comunitária jamais havia sido implementado nesta localidade; 2) a prevalência inicial da infecção era razoavelmente semelhante àquela observada em Patis $(38,2$ e 43,1\%, respectivamente) (Tabela 1); e3) por ser a localidade que apresentava maior número de habitantes no município de Mirabela, proporcionando estabilidade para as estimativas de prevalência. Patis e Muquem distam cerca de $20 \mathrm{~km}$ uma da outra, mas a comunicação é difícil porque a estrada é ruim e não existe transporte regular entre elas.

\section{Atividades do PCE/PCDE na área estudada}

As atividades do PCE/PCDEN na área estudada incluíam censo completo de cada localidade, identificação das coleções hídricas, levantamento malacológico e coproscopia pelo método de Kato-Katz. As seguintes medidas foram adotadas como parte do programa de controle: 1) aplicação de moluscicidas quando caramujos (Biomphalaria $s p$ ) infectados ou não eram encontrados; 2) tratamento gratuito de todos os moradores com exames de fezes positivos para ovos de $S$. mansonie tratamento daqueles com 7-14 anos de idade, independente do status da infecção; e 3) transmissão de informações sobre transmissão e prevenção da esquistossomose pelos "guardas" da Fundação Nacional de Saúde (antiga SUCAM), quando entregavam o remédio para tratamento. Estas atividades foram realizadas pela mesma equipe em ambas as comunidades em 1984, 1985, 1988, 1990 e 1994.

As atividades de mobilização comunitária tinham por objetivo aumentar o conhecimento sobre a prevenção da esquistossomose e mudar o comportamento dos moradores de áreas endêmicas em relação aos contatos com coleções hídricas ${ }^{1}$. Essas atividades foram desenvolvidas na localidade de Patis entre maio e novembro de 1989, por uma equipe treinada de educadores da Fundação Nacional de Saúde, tendo os escolares (7-14 anos de idade) e organizações comunitárias como alvo. As atividades foram 
desenvolvidas em duas fases. Na primeira, buscou-se determinar os conhecimentos básicos sobre higiene e sobre a esquistossomose e estabelecer as melhores formas para a abordagem da comunidade. Isto foi feito através de reuniões com professores, escolares e líderes formais e informais da comunidade. As atividades de mobilização comunitária propriamente ditas foram realizadas no momento seguinte, contemplando palestras para escolares e cursos de treinamento para professores, elaboração com a ajuda de escolares - de cartilha com informações sobre transmissão e prevenção da esquistossomose e uma marcha tendo a esquistossomose como tema. Maiores detalhes podem ser vistos em Uchoa et al. ${ }^{8}$.

\section{Coleta de dados}

O presente trabalho possui dois componentes. No primeiro, foram utilizados dados secundários para determinar a prevalência da infecção pelo $S$. mansoni antes e após o programa de mobilização comunitária nas duas comunidades. O segundo componente consistiu em um estudo de base populacional desenvolvido em Patis e Muquem no ano de 1995 para a obtenção de informações sóciodemográficas e informações sobre contatos com águas e conhecimentos acerca da esquistossomose e sua transmissão.

\section{Dados secundários}

As informações para o estudo de prevalência da infecção foram obtidas através da verificação de arquivos existentes na sede do Distrito Sanitário de Montes Claros ou na sede regional da Fundação Nacional de Saúde em Belo Horizonte. Foram utilizadas as fichas adotadas na rotina do serviço, correspondentes ao resumo mensal de atividades de coproscopia por localidade e ao resumo mensal de atividades de malacologia por localidade. Além disso, tendo por base dados correspondentes às atividades diárias de coproscopia e tratamento, foi construído um banco de dados com informações sobre a faixa etária dos habitantes. As seguintes in- formações foram consideradas: ano da atividade, número de habitantes, número e resultado dos exames de fezes, número de pessoas elegíveis para o tratamento e número de pessoas tratadas ${ }^{2}$.

\section{Dados primários}

Cada localidade foi mapeada e todos os domicílios numerados. Foi selecionada uma amostra probabilística simples, sem reposição, de 390 e 302 moradores com 2 + anos de idade em Patis e Muquem, respectivamente. As premissas assumidas para o cálculo do tamanho da amostra foram as seguintes: tamanho da população com $2+$ anos = 1374 (Patis) e 677 (Muquem); prevalência de contatos com águas $=0,15$; precisão $=$ 0,03 e intervalo de confiança $=0,95^{9}$. As questões relativas a conhecimentos sobre a esquistossomose foram respondidas somente pelos participantes com 10 + anos de idade. As demais informações foram prestadas pelo entrevistado ou com a ajuda da mãe ou responsável quando o entrevistado era menor de 10 anos de idade. Um consentimento pós informação assinado foi obtido de todos os participantes com 18+ anos de idade ou foi assinado por um responsável quando se tratava de participante mais jovem.

Todas as observações e entrevistas foram feitas pela mesma equipe nas duas localidades. Quatro conjuntos de informações foram considerados: (a) características do domicílio; (b) características demográficas dos moradores; (c) motivos e freqüências de contatos com coleções hídricas; (d) grau de conhecimento sobre a esquistossomose e fonte desse conhecimento. Para os três conjuntos iniciais foi utilizado um questionário com perguntas estruturadas e pré-codificadas. Para o último conjunto, as perguntas foram abertas e posteriormente foi feita a codificação de conteúdo ${ }^{8}$.

\section{Características dos domicílios}

As informações foram obtidas através da observação das características dos domicílios. Foram considerados: fonte de água (au- 
sente, presente sem torneira dentro de casa e presente com torneira dentro de casa), chuveiro (presente ou ausente), fossa (presente ou ausente) e distância do domicílio em relação ao córrego mais próximo $(<100$ ou $100+$ metros). As únicas fontes de abastecimento nas duas localidades eram cisterna ou poço artesiano e não havia sistema de esgoto.

Características demográficas e motivos de contatos com águas

Estas informações foram obtidas através de entrevista. Foram consideradas as seguintes características: idade (2-9, 10-19 e $\geq 20$ anos), sexo, tempo de residência na localidade e os contatos com coleções hídricas nos 12 meses que precederam a entrevista. Os seguintes motivos de contatos foram considerados: atividades de lazer (nadar/brincar e pescar); atividades domésticas e higiene pessoal (lavar roupas, lavar vasilhas, buscar água para utilização no domicílio e tomar banho); atividades ocupacionais (regar hortas, trabalhar em plantio irrigado ou em alagados e retirar areia), travessia de rios ou córregos e outros motivos.

\section{Conhecimentos sobre a esquistossomose}

Este conjunto incluiu quatro perguntas abertas: (1) se já havia ouvido falar de esquistossomose/xistose; (2) como se pegava a esquistossomose/xistose; (3) como se evitava a esquistossomose/xistose e (4) como essas informações foram obtidas. Para o primeiro item as respostas foram codificadas como sim ou não. Para os dois itens seguintes, a codificação foi feita como sim se a resposta incluía contatos com água (por qualquer dos motivos listados acima e/ ou entrar com água contaminada por fezes). Para o último item, as respostas foram classificadas em quatro grupos: SUCAM (nome pelo qual a Fundação Nacional de Saúde era conhecida nas localidades), igreja, escola e outras fontes. Maiores detalhes podem ser vistos em trabalho anterior ${ }^{8}$.

\section{Análise dos dados}

Para orientar a interpretação dos resultados foram utilizados os testes do qui-quadrado de Pearson, teste exato de Fischer (para variáveis discretas) ou teste de ordenação de Wilcoxon (para variáveis contínuas). Odds ratios foram utilizados para determinar a força de associações entre variáveis ${ }^{10}$. A regressão logística múltipla ${ }^{11}$ foi usada para determinar o efeito independente de cada variável. Foram incluídas no modelo logístico inicial todas as variáveis que apresentaram associações com contatos com águas em níveis de significância inferiores a 0,20 na análise bivariada. A variável relativa ao conhecimento sobre a transmissão da esquistossomose foi considerada a priori variável de confusão no estudo. As análises foram realizadas utilizando-se os softwares Epi-info ${ }^{9}$ Stata $^{12}$.

\section{Resultados}

Na Tabela 1 é apresentada a prevalência da infecção pelo $S$. mansoni em Patis e Muquem entre 1984 e 1994, assim como o número de habitantes e a proporção daqueles submetidos a coproscopia. Em ambas as localidades houve uma queda brusca da prevalência da infecção após a primeira intervenção realizada em 1984 (de 43,1 para $10,2 \%$ em Patis e de 38,2 para 5,5\% em Muquem). A partir daí a prevalência da infecção evoluiu de forma distinta nas duas localidades. Em Muquem, a prevalência aumentou progressivamente a partir de 1988, aproximando-se em 1994 do valor observado antes do início do PCE/PCDEN (33,7\%). Em Patis, ao contrário, a prevalência da infecção pelo $S$. mansoni ficou estacionada em torno de $10 \%$ entre 1985 e 1990 e subiu para 19,1\% em 1994.

A cobertura dos exames de fezes na população de ambas as localidades foi alta (mediana no período $=93,4$ e 95,4\% em Patis e Muquem, respectivamente; $\mathrm{p}=0,754)$. Também foi alta a cobertura do tratamento com oxamniquine, embora a proporção de tra- 
Tabela 1 - Prevalência da infecção pelo Schistosoma mansoni em Patis e Muquem (Minas Gerais, 1984-94)

Table 1 - Prevalence of Schistosoma mansoni infection in Patis and Muquem (Minas Gerais, 1984-94)

\begin{tabular}{|c|c|c|c|c|c|c|}
\hline \multirow{3}{*}{ Ano } & \multicolumn{3}{|c|}{ Patis * } & \multicolumn{3}{|c|}{ Muquem ${ }^{\dagger}$} \\
\hline & No. & $\%$ & $\%$ & No. & $\%$ & $\%$ \\
\hline & Habitantes & Examinados $\S$ & Positivos ** & Habitantes & Examinados $\S$ & Positivos ** \\
\hline 1984 & 1244 & 98,2 & 43,1 & 545 & 95,6 & 38,2 \\
\hline 1985 & 1174 & 90,2 & 10,2 & 598 & 94,5 & 5,5 \\
\hline 1988 & 1312 & 91,1 & 10,7 & 605 & 95,4 & 29,3 \\
\hline 1990 & 1255 & 93,2 & 9,7 & 570 & 96,0 & 22,3 \\
\hline 1994 & 1452 & 89,4 & 17,2 & 715 & 93,0 & 33,7 \\
\hline
\end{tabular}

"Localidade onde ocorreram atividades de mobilização comunitária em 1989/ Site with community mobilization activities in 1989 † Localidade onde não ocorreram atividades de mobilização comunitária em 1989/ Site without community mobilization activities in 1989

$\$$ \% calculado em relação ao total de habitantes/\% calculated in relation to total number of inhabitants

** calculado em relação ao total de examinados/ \% calculated in relation to tota Inumber of inhabitants

tados tenha sido mais baixa em Patis do que em Muquem (mediana no período $=79,2 \mathrm{e}$ $89,2 \%$, respectivamente; $\mathrm{p}=0,009$ ).

Na Tabela 2 estão apresentadas algumas características dos domicílios de Patis e Muquem no ano de 1995. A distribuição da fonte de água era semelhante nas duas loca- lidades (somente 8,8\% não possuíam fonte de água). A proporção de domicílios com chuveiro era maior em Patis em comparação com Muquem (39,2 vs. 20,0\%), assim como a proporção de domicílios com fossa (82,4 vs. $66,3 \%$ ). Em Muquem, $26,6 \%$ dos domicílios situavam-se a menos de 100

Tabela 2 - Distribuição dos domicílios estudados, segundo a fonte de água, a existência de chuveiro, fossa e córregos próximos em Patis e Muquem (Minas Gerais, 1995)

Table 2 - Distribution of households studied, according to water supply, existence of a shower, cesspool and nearest streams in Patis and Muquem (Minas Gerais, 1995)

\begin{tabular}{|c|c|c|}
\hline Variáveis & Patis $^{*}(n=102)$ & Muquem ${ }^{+}(n=80)$ \\
\hline \multicolumn{3}{|l|}{ Fonte de água (cisterna ou poço artesiano) } \\
\hline Ausente & 8,8 & 8,8 \\
\hline Presente sem torneira dentro de casa & 77,5 & 85,0 \\
\hline \multirow[t]{2}{*}{ Presente com torneira dentro de casa } & 13,7 & 6,3 \\
\hline & \multicolumn{2}{|c|}{$p=0,257$} \\
\hline \multicolumn{3}{|l|}{ Chuveiro } \\
\hline Ausente & 60,8 & 80,0 \\
\hline \multirow[t]{2}{*}{ Presente } & 39,2 & 20,0 \\
\hline & \multicolumn{2}{|c|}{$p=0,005$} \\
\hline \multicolumn{3}{|l|}{ Fossa } \\
\hline Ausente & 17,6 & 33,8 \\
\hline \multirow[t]{2}{*}{ Presente } & 82,4 & 66,3 \\
\hline & \multicolumn{2}{|c|}{$\mathrm{p}=0.012$} \\
\hline \multicolumn{3}{|l|}{ Distância em relação ao córrego mais próximo } \\
\hline$<100$ metros & 0,0 & 26,2 \\
\hline \multirow[t]{2}{*}{$\geq 100$ metros } & 100,0 & 73,8 \\
\hline & \multicolumn{2}{|c|}{$p<0,001$} \\
\hline
\end{tabular}

"Localidade onde ocorreram atividades de mobilização comunitária em 1989/ Site with community mobilization activities in 1989 † Localidade onde não ocorreram atividades de mobilização comunitária em 1989/ Site without community mobilization activities in 1989

p:valor de $\mathrm{p}$ (teste do qui quadrado de Pearson) / $p$ : $p$ value (Pearson's chi-square test) 
metros do córrego mais próximo, ao passo que em Patis, nenhum domicílio situava-se tão perto dos córregos.

A população das duas localidades não diferia em relação à idade, sexo e mediana do tempo de residência (Tabela 3 ).

A freqüência de contatos com águas foi menor em Patis do que em Muquem. Na primeira, $41,5 \%$ negaram ter tido contatos nos últimos 12 meses, $36,4 \%$ tiveram contatos menos de uma vez por semana e $22,1 \%$ relataram contatos semanais. Os dados correspondentes para os moradores da área controle foram 4,1, 11,6 e 84,2\%, respectivamente $(\mathrm{p}<0,001)$.

A distribuição dos motivos de contatos com coleções hídricas nos últimos 12 meses nas duas localidades está apresentada na Tabela 4. Contatos para atividades domésticas e higiene pessoal (lavar roupas, lavar vasilhas, buscar água para o domicílio e tomar banho) foram significativamente menos observados em Patis do que em Muquem, assim como os contatos para atividades ocupacionais, para nadar e para atravessar os rios ou córregos. Os contatos devido à pesca e a outros motivos não diferiram en- tre as duas localidades.

Os conhecimentos sobre a esquisossomose foram semelhantes nas duas localidades: em Patis e Muquem, 98,8 e 99,0\% dos entrevistados já haviam ouvido falar sobre a esquistossomose ( $\mathrm{p}=1,000)$ e 88,2 e 91,9\%, respectivamente, sabiam que a transmissão da esquistossomose ocorre através de contatos com águas $(\mathrm{p}=0,188)$. A SUCAM/FNS foi apontada como a principal fonte de informações de conhecimentos sobre a esquistossomose (46,9 e 51,7 \% relataram; $\mathrm{p}=0,029)$, seguida por outras fontes $(42,8 \mathrm{e}$ $41,4 \%$; $\mathrm{p}=0,763)$, escola $(28,8$ e $7,1 \%$; $p<0,001)$ e igreja $(0,7$ e $1,0 \%$, respectivamente; $\mathrm{p}=1,000$ ).

A análise não ajustada dos fatores associados aos contatos com águas nos últimos 12 meses entre moradores de Patis mostrou que somente a faixa etária e o sexo estavam significativamente associados aos contatos com águas. Fonte de água para o domicílio, presença ou não de chuveiro, presença ou não de fossa e conhecimentos sobre a esquistossomose não apresentaram associações significantes com contatos com águas naturais (Tabela 5).

Tabela 3 - Distribuição da população estudada, segundo a idade, o sexo e o tempo de residência em Patis e Muquem (Minas Gerais, 1995)

Table 3 -Distribution of population studied, according to age, sex and time of residence in Patis and Muquem (Minas Gerais, 1995)

\begin{tabular}{|c|c|c|}
\hline Variáveis & $\begin{array}{c}\text { Patis * \% } \\
(n=371)\end{array}$ & $\begin{array}{l}\text { Muquem }{ }^{\dagger} \\
(n=292) \%\end{array}$ \\
\hline \multicolumn{3}{|l|}{ Faixa etária (anos) } \\
\hline $2-9$ & 25,9 & 29,1 \\
\hline $10-19$ & 27,0 & 23,6 \\
\hline \multirow[t]{2}{*}{$\geq 20$} & 47,3 & 47,2 \\
\hline & \multicolumn{2}{|c|}{$p=0,513$} \\
\hline \multicolumn{3}{|l|}{ Sexo } \\
\hline Masculino & 52,8 & 46,2 \\
\hline \multirow[t]{2}{*}{ Feminino } & 47,2 & 53,8 \\
\hline & \multicolumn{2}{|c|}{$p=0,092$} \\
\hline Mediana do tempo de residência & $12,0(1-75)$ & $11,5(2-89)$ \\
\hline na localidade (amplitude) & \multicolumn{2}{|c|}{$p^{\prime \prime}=0,784$} \\
\hline
\end{tabular}


Tabela 4 - Distribuição dos motivos de contatos com águas nos últimos 12 meses entre residentes Patis e Muquem (Minas Gerais, 1995)

Table 4 - Distribution of reasons for water contact in 12 previous months among residents of Patis and Muquem (Minas Gerais, 1995)

\begin{tabular}{lccc}
\hline Motivos de contatos & $\begin{array}{c}\text { Patis }{ }^{*} \% \\
(\mathrm{n}=371)\end{array}$ & $\begin{array}{c}\text { Muquem }{ }^{+} \% \\
(\mathrm{n}=292)\end{array}$ & OR(IC 95\%) \\
\hline A. Lazer & 36,9 & 46,6 & $0,67(0,49-0,92)$ \\
Nadar & 14,3 & 15,8 & $0,89(0,58-1,37)$ \\
Pescar & & & \\
B. Atividades domésticas e higiene pessoal & 9,7 & 40,8 & $0,16(0,10-0,24)$ \\
Lavar roupas & 7,8 & 17,8 & $0,39(0,24-0,63)$ \\
Lavar vasilhas & 13,1 & 75,0 & $0,05(0,03-0,08)$ \\
Buscar água para o domicílio & 28,8 & 74,5 & $0,14(0,10-0,19)$ \\
Tomar banho & & & \\
C. Outros & 11,3 & 30,1 & $0,30(0,20-0,44)$ \\
Ocupacional & 38,0 & 83,6 & $0,12(0,08-0,18)$ \\
Atravessar rios ou córregos & 23,2 & 21,6 & $1,10(0,76-1,59)$ \\
Outras &
\end{tabular}

"Localidade onde ocorreram atividades de mobilização comunitária em 1989 / Site without community mobilization activities in 1989

+ Localidade onde não ocorreram atividades de mobilização comunitária em 1989/ Site without community mobilization activities in 1989

$\%$ : Percentagem que relataram ter contatos por este motivo/ \%: Percentage that stated contact for this reason

OR (IC 95\%): Odds ratio (intervalo de confiança em nível de 95\%); a classe de referência foi constituída por aqueles que negaram contatos por este motivo. / OR (Cl 95\%):Odds ratio (95\% confidence interval): reference class comprises individuals who denied contact for this reason

A associação entre contatos com águas, faixa etária e sexo entre os moradores de Patis persistiram após os ajustamentos por variáveis de confusão. Faixa etária (10-19 e $\geq$ 20 anos) e sexo (masculino) mantiveram-se associadas de forma independente com esses contatos. (Tabela 6).

\section{Discussão}

Os resultados do presente trabalho mostram tendências diferentes na evolução da prevalência da infecção pelo $S$. mansoni nas localidades estudadas. Em Patis, onde atividades de mobilização comunitária foram desenvolvidas, a prevalência da infecção permaneceu baixa por um longo período (19851990) e aumentou em 1994, sem atingir os valores observados antes do início do programa de controle da esquistossomose. Em Muquem, ao contrário, a prevalência ascendeu progressivamente entre 1985 e 1990, e em 1994 já havia atingido índice semelhante ao observado antes do início das atividades do programa acima mencionado. Entretanto, essas diferenças não parecem estar relacionadas à mobilização comunitária realizada em Patis, uma vez que, quando estas atividades aconteceram (1989), a prevalência da infecção já se encontrava em patamares baixos e assim permaneceu até o ano seguinte. Além disso, em 1994 verificou-se um aumento da prevalência da infecção pelo $S$. mansoni em ambas as localidades, assim como em todo o município de Mirabela, provavelmente como conseqüência do aumento do intervalo entre tratamentos ${ }^{2}$.

As duas localidades apresentavam semelhanças e diferenças importantes. As principais semelhanças referiam-se à cobertura de abastecimento de água nos domicílios, à prevalência inicial da infecção pelo $S$. mansoni, à uniformidade na condução das demais atividades para o controle da esquistossomose e aos conhecimentos sobre a mesma. As principais diferenças eram maior proximidade dos domicílios de Muquem com os córregos, maior freqüência de conta- 
Tabela 5 - Distribuição dos contatos com águas nos últimos 12 meses, segundo características selecionadas (Patis'1, 1995)

Table 5 - Distribution of water contacts in previous 12 months, according to selected characteristics

\begin{tabular}{|c|c|c|c|}
\hline \multirow[t]{2}{*}{ Variáveis } & \multicolumn{2}{|c|}{ Relataram contato } & \multirow[t]{2}{*}{ OR(IC 95\%) } \\
\hline & $\operatorname{Sim}(n) \%$ & Não (n) \% & \\
\hline \multicolumn{4}{|c|}{ Faixa etária (anos) } \\
\hline $2-9$ & $42(19,4)$ & $54(35,1)$ & 1,00 \\
\hline $10-19$ & $75(34,6)$ & $25(16,2)$ & $3,86(2,10-7,07)$ \\
\hline$\geq 20$ & $100(46,1)$ & $75(48,7)$ & $1,71(1,04-2,83)$ \\
\hline \multicolumn{4}{|c|}{$P<0,001$} \\
\hline \multicolumn{4}{|l|}{ Sexo } \\
\hline Feminino & $85(39,2)$ & $90(58,4)$ & 1,00 \\
\hline Masculino & $132(60,8)$ & $64(41,6)$ & $2,18(1,43-3,33)$ \\
\hline \multicolumn{4}{|c|}{$P<0,001$} \\
\hline \multicolumn{4}{|c|}{ Cisterna ou poço artesiano no domicílio } \\
\hline Ausente & $13(6,0)$ & $9(5,8)$ & 1,00 \\
\hline Presente & $204(94,0)$ & $145(94,2)$ & $0,97(0,41-2,34)$ \\
\hline \multicolumn{4}{|c|}{$\mathrm{p}-0,953$} \\
\hline \multicolumn{4}{|c|}{ Chuveiro no domicílio } \\
\hline Ausente & $154(71,0)$ & $109(70,8)$ & 1,00 \\
\hline Presente & $63(29,0)$ & $45(29,2)$ & $0,99(0,63-1,56)$ \\
\hline \multicolumn{4}{|c|}{$P=0,969$} \\
\hline \multicolumn{4}{|l|}{ Fossa } \\
\hline Ausente & $32(14,7)$ & $31(20,1)$ & 1,00 \\
\hline Presente & $185(85,3)$ & $123(79,9)$ & $1,46(0,85-2,51)$ \\
\hline \multicolumn{4}{|c|}{$P=0,174$} \\
\hline \multicolumn{4}{|c|}{ Já havia ouvido falar de esquistossomose ${ }^{1}$} \\
\hline Não & $3(1,7)$ & $0(0,0)$ & - \\
\hline Sim & $170(98,3)$ & $98(100,0)$ & - \\
\hline \multicolumn{4}{|c|}{$P^{\prime}=0,556$} \\
\hline \multicolumn{4}{|c|}{ Sabia que a transmissão ocorria através de contatos com água * } \\
\hline Não & $50(28,0)$ & $26(26,5)$ & 1,00 \\
\hline Sim & $123(71,1)$ & $72(73,5)$ & $0,88(0,51-1,55)$ \\
\hline \multicolumn{4}{|c|}{$P=0,676$} \\
\hline
\end{tabular}

${ }^{*}$ Somente pessoas com ${ }^{3} 10$ anos de idade/ Only individuals ${ }^{3} 10$ years of age

OR(IC 95\%): Odds ratio (intervalo de confiança em nível de 95\%)/ OR (CI 95\%):Odds ratio (95\% confidence interval) $\mathrm{p}$ :valor de $\mathrm{p}$ (teste do qui quadrado de Pearson) / $p$ : $p$ value (Pearson's chi-square test)

$p^{\prime}$ : valor de $\mathrm{p}$ (teste exato de Fischer) / $p^{\prime}: p$ value (Fischer's Exact test)

Tabela 6 - Resultados estatísticamente significantes $(p<0,05)$ da análise multivariada dos fatores associados aos contatos com águas nos últimos 12 meses (Patis, 1995)

Table 6 - Statistically significant results $(p<0.05)$ by multivariate analysis of factors associated with water contact in previous 12 months (Patis, 1995)

\begin{tabular}{lc}
\hline Variáveis & Odds ratio ajustado (IC 95\%) \\
\hline Faixa etária (anos) & 1,00 \\
$2-9$ & $4,0(2,1-7,4)$ \\
$10-19$ & $1,9(1,1-3,2)$ \\
$\geq 20$ & \\
Sexo & 1,00 \\
$\quad$ Feminino & $2,2(1,4-3,5)$ \\
$\quad$ Masculino & \\
\hline
\end{tabular}

Odds ratio (intervalo de confiança ao nível de 95\%) ajustado pelo método de regressão logística múltipla; todos os participantes ( $n$-371) foram incluídos no modelo final listado na tabela. O modelo inicial incluiu faixa etária, sexo, fossa no domicílio e saber que a transmissão ocorre através de contatos com águas.

Odds ratio [(95\% confidence interval) adjusted by multiple logistic regression method; all participants ( $n$ - 371$)$ were included in the final model listed in the table. The initial model included age group, sex, home cesspool and knowledge that transmission occurs through contact with water] 
tos com águas nessa localidade e predomínio de contatos que podem ser atribuídos à necessidade (atividades domésticas, higiene pessoal e contatos ocupacionais).

É desejável neste tipo de investigação que as localidades comparadas sejam semelhantes em tudo, exceto na intervenção sob avaliação (no caso, mobilização comunitária). Entretanto, não havia outras opções para a seleção de localidades no município de Mirabela, uma vez que todas as demais possuíam menos de 250 habitantes. A opção por uma comunidade controle, situada em outro município, poderia introduzir vieses na interpretação dos resultados devido a eventuais diferenças entre as equipes que conduziram as atividades do PCE/PCDEN² . Além disso, nos demais municípios da região não haviam sido realizados exames de fezes após 1990; como as atividades de mobilização comunitária foram desenvolvidas em 1989, o período para acompanhamento posterior ficaria muito curto.

A explicação para as diferenças na evolução da prevalência da infecção pelo $S$. mansoninas duas localidades não é evidente. As medidas de controle da esquistossomose foram as mesmas, exceto as atividades de mobilização comunitária, e a validade interna dos dados estava assegurada pela alta cobertura do programa. Foi observada maior cobertura de tratamento em Patis, mas é de se esperar que a influência deste fenômeno fosse na direção oposta (maior prevalência da infecção nesta comunidade) àquela observada no presente trabalho. A proporção de domicílios com fonte de água era semelhante e não poderia explicar as diferenças nos padrões de contatos com água encontrados. A explicação surgiu durante os trabalhos de campo, quando houve paralisação do fornecimento de água em Muquem devido à quebra da bomba do sistema de abastecimento ${ }^{8}$. Soubemos então que este fenômeno era freqüente e, acrescido da proximidade dos córregos, parece ser a explicação mais provável para a recorrência da infecção em patamares tão altos nesta localidade.

Um dos principais objetivos da presente investigação era examinar os fatores deter- minantes dos contatos com águas na localidade de Patis, sobretudo a existência de associação entre conhecimentos sobre a esquistossomose e exposições de risco. Em Muquem, investigação semelhante não pôde ser conduzida porque $96 \%$ dos entrevistados relataram ter tido contatos com água nos últimos 12 meses, ou seja, virtualmente toda a população estava exposta a esses contatos. Nossos resultados mostram que somente idade e sexo estavam independentemente associados aos contatos com coleções hídricas em Patis. Conhecimentos sobre a transmissão e prevenção da esquistossomose não estavam associados aos contatos com águas, assim como a existência de abastecimento de água no domicílio. Este resultado não é uma surpresa, porque as principais razões para os contatos com águas em Patis eram natação (37\% relataram) e travessia dos córregos (38\%), razões não relacionadas ao abastecimento de água no domicílio.

No que se refere ao delineamento desta investigação, três opções foram inicialmente consideradas. A primeira levava em conta a possiblidade da condução de um estudo ecológico. A principal vantagem seria a validade externa do estudo, uma vez que diversas localidades poderiam ser estudadas simultaneamente. A principal desvantagem seria aquela inerente a este tipo de delineamento: dificuldade para controlar variáveis de confusão e viés ecológico ${ }^{13}$. Além disso, este delineamento não teria sido possível porque programas de mobilização comunitária em Minas Gerais voltados para a esquistossomose como parte do PCE/ PCDEN não haviam sido desenvolvidos naquela época em outra localidade além de Patis. A segunda opção seria o delineamento seccional, considerando a infecção pelo $S$. mansoni como variável dependente ${ }^{14,15}$. A principal vantagem seria a possibilidade de determinar fatores sócio demográficos e padrões de contatos com águas associados à infecção. Por outro lado, a principal desvantagem seria a impossibilidade de se estabelecer uma relação temporal entre infecção e contatos com água. Este delineamento 
também não seria viável porque a população das duas localidades havia sido tratada em 1994. A falha terapêutica da oxamniquine ocorre em cerca de $30 \%$ dos indivíduos submetidos ao tratamento ${ }^{16} \mathrm{e}$ a reinfecção aumenta com o tempo decorrido após o mes$\mathrm{mo}^{17,18}$. Na presente situação, um ano após o tratamento, os resultados seriam inconclusivos porque seria impossível separar os efeitos da reinfecção e da falha terapêutica. Resultados da coproscopia realizada em 1994 também não poderiam ter sido utilizados porque os pacientes já haviam sido informados dos resultados deste exame e, como conseqüência, poderiam ter mudado o seu comportamento. A opção viável foi o desenvolvimento de um estudo seccional, considerando os contatos com águas nos últimos 12 meses como variável dependente. A principal vantagem desta opção foi possibilitar a investigação do eixo das atividades de educação para saúde, ou seja, comportamentos de risco e conhecimentos sobre transmissão e prevenção da esquistossomose. O problema da temporalidade neste caso parece não ter existido porque não há indícios de que as variáveis consideradas (características sócio demográficas, saneamento do domicílio e conhecimentos sobre a esquistossomose) tenham se modificado ao longo dos 12 meses que precederam o estudo (período de abrangência adotado para a informação sobre contatos com água), uma vez que não houve melhora ou piora do saneamento da área nem campanhas educativas para a esquistossomose.

Em resumo, o modelo conceitual implícito no programa de mobilização comunitária era que: primeiro, este levaria a um aumento do conhecimento; segundo, o aumento de conhecimentos levaria a uma mudança de comportamentos; terceiro, estas mudanças levariam à redução na prevalência da infecção pelo $S$. mansoni. Nossos resultados mostram que isto não aconteceu, como exposto a seguir:

(1) A distribuição dos conhecimentos sobre a prevenção e transmissão da esquistossomose era semelhante nas duas localidades, sugerindo que as atividades de mobilização comunitária (realizada somente em uma delas) não influenciaram este conhecimento. Na realidade, este conhecimento parece ter sido transmitido pelos "guardas da SUCAM", como descrito anteriormente ${ }^{8}$, que atuaram de forma semelhante em ambas as comunidades;

(2) Os conhecimentos sobre prevenção e transmissão da esquistossomose não parecem ter influenciado o comportamento das populações estudadas em relação aos contatos com águas. Esta afirmativa baseia-se nos seguintes resultados: primeiro, a distribuição dos conhecimentos sobre a esquistossomose era semelhante nas duas comunidades, mas os padrões de contatos com águas eram diferentes; segundo, estes conhecimentos não estavam associados aos contatos com águas em Patis (onde o programa de mobilização comunitária foi conduzido). As explicações para esses resultados são duas. A primeira está relacionada à necessidade de contatos com águas na área controle devido a falhas periódicas no sistema de distribuição de água e à facilidade para estes contatos devido à maior proximidade com os córregos. A segunda está relacionada às representações e comportamentos em relação à esquistossomose das populações estudadas, como mostrado em publicação anterior ${ }^{8}$ : a percepção de proteção conferida pelo tratamento reduzia a importância de evitar contatos com águas nas comunidades estudadas, apesar dos conhecimentos sobre a transmissão e prevenção da esquistossomose.

(3) A maior redução da prevalência da infeção pelo $S$. mansoni observada em Patis, em comparação à área controle, deve-se provavelmente a causas externas e não ao programa de mobilização comunitária.

Programas para o controle da esquistossomose baseados no tratamento em larga escala de populações residentes em áreas endêmicas são efetivos para a redução da prevalência da infecção pelo $S$. mansoni e 
sua morbidade ${ }^{19}$. Esses programas, entretanto, são caros e exigem atividades permanentes de controle na área endêmica, uma vez que a interrupção do tratamento pode ter como conseqüência o aumento da prevalência da infecção pelo parasita². Para que os benefícios desses programas se mantenham a longo prazo são necessários investimentos em saneamento básico e educação para a saúde. Nossos resultados são um exemplo de como essas metas são difíceis de serem alcançadas quando o tratamento e não o saneamento e a educação para a saúde são as atividades prioritárias dentro de um programa de controle da esquistossomose.

\section{Agradecimentos}

Os autores gostariam de agradecer ao Dr. Cesar Victora pela revisão crítica do manuscrito e ao Dr. Carlos Catão Prates Loiola da Fundação Nacional de Saúde, sem cujo apoio este estudo não teria sido viável.

\section{Referências}

1. Ministério da Saúde. Superintendência de Campanhas. Documento elaborado para apresentação ao Banco Internacional de Reconstrução e Desenvolvimento. Brasília (DF); 1987.

2. Lima e Costa MFF, Guerra HL, Pimenta Júnior FG, Firmo JOA, Uchoa E. Avaliação do programa de controle da esquistossmose (PCE/PCDEN) em municípios situados na Bacia do Rio São Francisco, Minas Gerais, Brasil. Rev Soc Bras Med Trop 1996; 29: 117-26.

3. Ministério da Saúde, Fundação Nacional de Saúde, Regional de Minas Gerais Mobilização Comunitária FNS. Programa de controle da esquistossomose mansoni no Estado de Minas Gerais. Reunião de avaliação das atividades do Projeto de Controle de Doenças endêmicas do Estado de Minas Gerais (1989-1994). Belo Horizonte; 1994. p. 133-135.

4. Ekeh H and Adeniyi AD. Health education strategies for tropical disease control in school children. $J$ Trop Med Hyg 1998; 91: 55-59.

5. Schall VT, Dias AG, Malaquias ML, Dos Santos MG. Health education in $1^{\text {st }}$ grade public schools at the periphery of Belo Horizonte, MG, Brazil. I. Evaluation of the program relative to schistosomiasis. Rev Inst Med Trop 1993; 35: 563-72.

6. Kloos H. Human Behavior. Human behaviour, health education and schistosomiasis control: a review. Soc Sci Med 1995; 11: 1497-511.
7. Santana VS, Teixeira M da G, Santos CP, de Andrade CA. The effectiveness of the Program of Comunication and Education in Health on the control of $\boldsymbol{S}$. mansoni infection in some areas of the state of Bahia. Rev Soc Bras Med Trop 1997; 30: 447-56.

8. Uchoa E, Barreto SM, Firmo JOA, Guerra HL, Pimenta Jr FG, Lima e Costa MFF. The control of schistosomiasis in Brazil: an ethno-epidemiology study of the effectiveness of a community mobilization program for health education. Soc Sci Med 2000; 51: 1529-41.

9. Dean AG et al. Epi Info version 6.0: a word processing database and statistics program for epidemiology on microcomputers. Atlanta; Center for Disease Control and Prevention; 1994.

10. Armitage P, Berry G. Statistical Methods in Medical Research. Oxford, UK: Balckwell Scientific Publications; 1987.

11. Hosmer DW, Lemenshow S. Applied logistic Regression. New York, USA: Johns Wiley and Sons; 1989.

12. Stata Statistical Software [computer program]. Release 6.0 College Stations. Texas: Stata Corporation; 1997.

13. Morgenstern H. Ecologic Studies. In: Rothman J \& Greenland S. Modern Epidemiology. Philadelphia: Lippincott-Raven, $2^{\text {nd }}$ ed; 1998, p. 459-480. 
14. Firmo JOA, Lima e Costa MFF, Guerra HL \& Rocha RS. Urban schistosomiasis: morbidity, sociodemographic characteristics and water contact patterns predictive of infection. Intl J Epidemiol 1996; 25: 1292-300.

15. Lima e Costa MFF, Rocha RS, Firmo JOA, Guerra HL \& Katz N. Questionnaires in the screening for Schistosoma mansoni infection: a study of socio demographic and water contact variables in four communities in Brazil. Rev Inst Med Trop São Paulo 1998; 40: 31-7.

16. Lambertucci JR, Greco DB, Rocha MOC, Salazar HM, Pedroso EP \& Lima DP. A double blind trial with oxamniquine in chronic schistosomiasis mansoni. Trans R Soc Trop Med Hyg 1982; 76: 751-5.
17. Katz N. Experiências com quimioterapia em grande escala no controle da esquistossomose no Brasil. Rev Inst Med Trop São Paulo 1980; 22: 40-51.

18. Lima e Costa MFF, Rocha RS, Coura Filho P \& Katz N. A 13-year follow-up of treatment and small control in an area endemic for Schistosoma mansoni in Brazil: incidence of infection and reinfection. Bull World Health Organ 1993; 71: 197-205.

19. World Health Organisation. The control of Schistosomiasis. Geneva; 1994. (WHO - Technical Report Series, 830.)

Recebido em 04/01/02; aprovado em 15/08/02 